need for long term follow up to determine whether the entity that they have defined represents an early manifestation of dementia or a benign if inconvenient consequence of growing old. ${ }^{2}$ The National Institute of Mental Health's working group of which they were members published its criteria in $1986,{ }^{3}$ and yet six years later we still do not know the answer. This information is of more than academic interest as it is bound to affect the risk: benefit ratio of any drug advocated to improve memory in elderly people.

Crook and Ferris argue by analogy to presbyopia and its correction by means of lenses. A closer parallel might be the decline in physical prowess with age and its boosting with hormones. Both analogies are likely to be imperfect, and the issue is complex and unlikely to be resolved in the current state of knowledge. We do not automatically oppose the investigation of drugs to improve memory. What we want is more information about the baseline so that a more informed judgment may be made about the risks and benefits of their use.

JOHN O'BRIEN

Psychiatric Services for the Elderly,

Fulbourn Hospital,

Cambridge CBI SES

Section of Old Age Psychiatry,

RAYMOND LEVY

Institute of Psychiatry

London SE5 8AF

1 Crook $\mathrm{TH}$, Ferris $\mathrm{SH}$. Age associated memory impairment. BMJ 1992;304:714. (14 March.)

2 O'Brien JT, Levy R. Age associated memory impairment. BM7 1992;304:5-6.

3 Crook TH, Bartus RT, Ferris SH, Whitehouse P, Cohen GD, Gershon $S$, et al. Age associated memory impairment: proposed diagnustic criteria and measures of clinical change - report of a diagnostic criteria and measures of clinical change - report of National Institute of Mental Health wh

\section{Medical abortion}

SIR, - In their letters Peter Doherty and A P Cole allude to possible teratogenic effects of mifepristone. ${ }^{12}$ They refer to the sole case of multiple abnormalities seen at late abortion in a woman who had received mifepristone in early pregnancy in France in 1987. This case has been investigated and reported previously. No conclusion was possible as to whether the abnormalities were related to mifepristone or coincidental..$^{3-6}$

Women may change their mind and decide to continue their pregnancy to term despite exposure to mifepristone and prostaglandins. In fact, the incidence is very low, with only five known cases in over 100000 uses. No abnormalities occurred.

The responsible approach is to advise women clearly of the potential risk, as is done in the information leaflets on mifepristone, and for prescribers to follow rigorously the stated protocol, covering assessment, dosage, treatment schedule, and follow up.

JOAN BARNARD ANDRÉ ULMANN

Roussel Laboratories

Denham,

Uxbridge,

Middlesex UB9 $5 \mathrm{HB}$

1 Doherty P. Medical abortion. BMF 1992;304:573. (29 February. 2 Cole AP. Medical abortion. BMJ 1992;304:573. (29 February.) 3 Henrion R. RU 486 abortions. Nature 1989;338: 110.

4 Pons JC, Elefant E, Herckorn P, Papiernik E. Developmen after exposure to mifepristone in early pregnancy. Lance 1991;338:763.

5 Pons JC, Papiernik E. Mifepristone teratogenicity. Lance 1991;338:1332-3.

6 Ulmann A, Rubin I, Barnard J. Development after in-utero exposure to mifepristone. Lancet 1991;338:1270.

SIR,-Medical abortion using mifepristone (RU 486 ) in combination with a prostaglandin is a safe and effective alternative to surgical abortion in the early first trimester.' Although no rigorous economic evaluation has been reported, it has been suggested that this new treatment would lead to considerable financial savings to the NHS. We have recently completed an economic analysis as part of a wider study investigating the medical and psychological sequelae of medical and surgical abortion. As many purchasing authorities are currently negotiating contracts for abortion services, an interim report may be useful to decision makers.

Our analysis is based on a pragmatic randomised trial of 363 women, 172 of whom underwent medical abortion and 191 surgical abortion. Medical abortion was undertaken using mifepristone $600 \mathrm{mg}$ followed 36-48 hours later by gemeprost $1 \mathrm{mg}$ vaginal pessary. Surgical abortions were performed by vacuum aspiration under general anaesthesia. Ninety nine per cent of medical abortions and $91 \%$ of surgical abortions were completed as day cases. There were no significant differences in complete abortion or complication rates, which were consistent with previously reported studies. ${ }^{23}$ There were no persisting pregnancies.

We estimate that costs to the health board, including all outpatient services, investigations, inpatient services, and the management of complications occurring up to eight weeks after abortion were $£ 400$ for medical abortion and $£ 480$ for surgical abortion. Costs to the patients and to community health services are not included. Preliminary analysis suggests that there was little difference between the two groups in patients perceptions of outcome in general, and acceptability in particular.

In Grampian half of the 1200 women treated annually (virtually all in NHS premises) are managed before nine weeks' gestation. We have recently introduced a medical abortion service; this mirrors the experience in France, where about $20 \%$ of eligible women opt for medical abortion. We estimate that this will result in an annual financial saving to the health board of nearly $£ 10000$.

In England and Wales, although 79\% of women first approach a doctor before eight weeks' gestation, only $21 \%$ of abortions in NHS premises are performed before nine weeks' gestation; $68 \%$ of these women are managed as day cases. ${ }^{45}$ Until more women are referred promptly, the financial savings offered by medical abortion will not be realised. As morbidity and mortality increase with advancing gestation, ${ }^{3}$ it would be beneficial to al concerned for purchasing authorities to ensure that prompt referral is a high priority.

R C HENSHAW

Department of Obstetrics and Gynaecology,

Aberdeen Maternity Hospital, Aberdeen AB9 2ZD A A TEMPLETON

Health Services Research Unit,

S A NAJI

University of Aberdeen

Aberdeen AB9 2ZD

1 Heard M, Guillebaud J. Medical abortion. BMF 1992;304:195-6. (25 January.)

2 United Kingdom Multicentre Trial. The efficacy and tolerance of mifepristone and prostaglandin in first trimester termination of pregnancy. Br J Obstet Gynaecol 1990;97:480-6.

3 Castadot RG. Pregnancy termination: techniques, risks, and complications and their management. Fertil Steril 1986;45: 5-17.

4 Munday D, Francome C, Savage W. Twenty one years of legal abortion. BMF 1989;298:1231-4.

5 Office of Population Censuses and Surveys. Abortion statistics. London: HMSO, 1989.

SIR, - We agree with Peter Doherty' that in up to $1 \%$ of cases mifepristone plus prostaglandin may not terminate a pregnancy. A P Cole wrongly states that $6 \%$ will not abort ${ }^{2}$; in both the French and English experience this larger percentage required surgical intervention for retained products or bleeding.

Although there have been several pregnancies carried to term with no apparent abnormality, we also agree it should be presumed that mifepristone is capable of teratogenic effects in women. We made it clear in our article that a surgical termination should alsways follow if the process is either incomplete or the pregnancy fails to abort. Moreover, it is unlikely that there could be " 1000 malformations resulting from 100000 attempted abortions." This could be true only if $100 \%$ of fetuses in failed abortions had an abnormality (and none was identified in time to proceed to surgical abortion). The data available indicate that if pregnancies do continue only a proportion of fetuses have a malformation, though this risk is still unacceptable.

In practice, the most relevant circumstance will be when a woman changes her mind after receiving mifepristone. We recommend the initial consent includes a woman's agreement that she must take full responsibility for any outcome if the pregnancy continues as a result of any action or inaction on her part as there would be a risk of a birth defect.

MICHAEL HEARD JOHN GUILLEBAUD

University College Hospital,

London WC1E 6AU

Doherty P. Medical abortion. BM7 1992;304:573. (29 February.) 2 Cole AP. Medical abortion. BM7 1992;304:573. (29 February.)

\section{Functional iron deficiency during erythropoietin treatment}

SIR, - We read with interest the paper by Ian C Macdougall and colleagues. ' At our unit in 38 renal patients over the first 12 weeks of erythropoietin treatment, the haemoglobin concentration rose from 69 (SE 2) g/l to $104(0.3) \mathrm{g} / \mathrm{l}(\mathrm{p}<0.0001$, two tailed paired $t$ test). The (geometric) mean serum ferritin concentration declined from 219 (1) $\mu \mathrm{g} / \mathrm{l}$ to 94 (1) $\mu \mathrm{g} / \mathrm{l}(\mathrm{p}=0.014)$, but the serum transferrin saturation did not change significantly (from 29.9 $(3 \cdot 4) \%$ to $25 \cdot 2(2 \cdot 2) \%)$. The transferrin saturation correlated with ferritin initially $(r=0.75, p<0.001)$ but not after the first four weeks. At 12 weeks, eight of 15 patients with iron deficiency (ferritin concentration $<50 \mu \mathrm{g} / \mathrm{l}$ ) had a transferrin saturation $>20 \%$ whereas two of five patients with iron overload (ferritin concentration $>500 \mu \mathrm{g} / \mathrm{l}$ ) had a transferrin saturation $<20 \%$. In 14 patients with iron overload the haemoglobin concentration rose from $67(3) \mathrm{g} / \mathrm{l}$ to $99(4) \mathrm{g} / \mathrm{l}(\mathrm{p}<0.0001)$ entirely by mobilising iron reserves, which were reduced from $1220(73) \mathrm{mg}$ to $739(111) \mathrm{mg}(\mathrm{p}<0.001)$. In the 24 other patients haemoglobin rose similarly (from 70 (8) g/l to 107 (4) g/l; p <0.0001), partly by depleting iron reserves (from $224(78) \mathrm{mg}$ to $-54(83) \mathrm{mg}$; $\mathrm{p}=0.019)$ and partly by utilising orally absorbed iron (297 (119) mg)

In a previous study Macdougall et al concluded that the transferrin saturation was superior to the serum ferritin concentration for detecting functional iron deficiency and that parenteral iron was superior to oral iron. These conclusions were based on five patients who initially had low serum ferritin concentrations $(<50 \mu \mathrm{g} / \mathrm{l})$. They received only 35 $\mathrm{mg} /$ day of elemental iron. In other words, the patients alleged to have functional iron deficiency were probably truly iron deficient before erythropoietin treatment and became more so subsequently. In the absence of adequate oral iron supplements their response to erythropoietin was impaired; hence their reported response to parenteral iron.

Use of the transferrin saturation has considerable limitations, as the authors concede; the serum ferritin concentration is the best available parameter of iron stores. ${ }^{24}$ High transferrin saturation usually indicates iron overload, but a low value in renal failure (and other chronic diseases) may coexist with any iron status.

Erythrocyte hypochromia may prove to be 